Published by Al-Nahrain College of Medicine P-ISSN 1681-6579

E-ISSN 2224-4719

Email: iraqijms@colmed-alnahrain.edu.iq

http://www.colmed-alnahrain.edu.iq

http://www.iraqijms.net

Iraqi JMS 2018; Vol. 16(4)

\title{
Hodgkin Disease in Children
}

\author{
Sawsan S. Abbas ${ }^{1} C A B P$, Ruaa H. Ali ${ }^{2}$ FICMS \\ ${ }^{1}$ Dept. of Pediatrics, College of Medicine, Al-Nahrain University, Baghdad, Iraq, ${ }^{2}$ Dept. of Pediatrics, Al-Imamein Al- \\ Kadhimein Medical City, Baghdad, Iraq
}

\section{Abstract \\ Background}

Objective

Methods

Results

Conclusion

\section{Keywords Citation}

Hodgkin lymphoma $(\mathrm{HL})$ is a malignant process involving the lympho-reticular system that accounts for $6 \%$ of childhood cancers. Infectious agents may be involved, such as human herpes virus 6 , cytomegalovirus, and Epstein-Barr virus (EBV). Infection with EBV confers a 4-fold higher risk of developing $\mathrm{HL}$.

To have an idea about the mode of presentation, pathological subtypes, treatment applied and outcome in one center in our country.

A retrospective study was done whereby twenty cases were collected from the Pediatric Oncology Clinic in Al-Imamein AL-Kadhimein Medical City over a period of ten years from the first of January 2007 - end of December 2016. Information was taken from the patient's records in the Pediatric Oncology Clinic including age at presentation, sex, physical finding, histopathological subtypes, staging, treatment applied and outcome.

Among the studied group, 14 cases (70\%) were males and 6 cases (30\%) were females, male: female ratio equal to $2.3: 1$, rang of age was between 5-12 years with a peak age at presentation was between $5-7$ years, 12 cases (60\%). The initial presentation was an enlarged cervical lymph node in 19 of them (95\%), histopathologically, most of the patients had mixed cellularity subtype, 9 cases (45\%), stage II and stage III comprise the majority of cases 9 cases (45\%), 6 cases $(30 \%)$ respectively, B symptoms were reported in 7 cases (35\%). Chemotherapy was the mainstay of treatment with good response and remission, 17 cases (85\%). Three cases refractory to treatment (15\%) with no response, no death was reported.

Male predominance was noticed with younger age group at presentation. The majority presented with enlarged cervical lymph node. Although mixed cellularity was encountered in most of the patients, the response to chemotherapy was good. Rituximab can be used along with chemotherapy for refractory cases and for lymphocyte predominant Hodgkin lymphoma. Hodgkin Disease, Children

Abbas SA, Ali RH. Hodgkin disease in Children. Iraqi JMS. 2018; 16(4): 424-429. doi: 10.22578/IJMS.16.4.10
List of abbreviations: ABVD = Adriamycin, Bleomycin, Vinblastine, Dacarbazine, ABVP = Adriamycin, Bleomycin, Vinblastine, Predinsolone, $C D=$ Cluster of differentiation, Chlvpp = Chlorambucil, Vinblastine, Procarbazin, Prednisolone, $\mathrm{cHL}=$ classic Hodgkin lymphoma, $\mathrm{EBV}=$ Epstein-Barr virus, $\mathrm{HL}=$ Hodgkin lymphoma, $\mathrm{L} \& \mathrm{H}=$ Lymphocytic and histiocytic, $\mathrm{LP}-\mathrm{HL}=$ Lymphocyte predominance Hodgkin lymphoma, LPHD = Lymphocyte predominance Hodgkin disease, REAL = Revised European American lymphoma, UKCCSG: United Kingdome Children's Cancer Study group, WHO = World Health Organization

\section{Introduction}

$\mathrm{H}$ odgkin lymphoma ( $\mathrm{HL}$ ) is a malignant process involving the lympho-reticular system that accounts for $6 \%$ of childhood cancers ${ }^{(1)}$. Infectious agents may be involved, such as human herpes virus 6, cytomegalovirus, and Epstein-Barr virus (EBV). Infection with EBV confers a 4-fold higher risk 
of developing $\mathrm{HL}{ }^{(1)}$. A significant male-tofemale ratio of $3: 1$ is observed in children younger than 10 years. In older children and adults, the male-to-female ratio is about 1:1 (2). The REAL/WHO classification recognizes a basic distinction between lymphocyte predominance $\mathrm{HL}(\mathrm{LP}-\mathrm{HL})$ and classic $\mathrm{HL}(\mathrm{CHL})$, reflecting the differences in clinical presentation and behavior, morphology, phenotype, and molecular features. CHL has been classified into four subtypes: lymphocyte rich, nodular sclerosing, mixed cellularity, and lymphocyte depleted (3). Treatment in children evolved from extended-field radiation therapy to the use of multi- agent chemotherapy ${ }^{(1)}$. CD20 is detected in the malignant lymphocytic and histiocytic (L\&H) cells of almost all Hodgkin disease of lymphocyte predominance (LPHD) type, the neoplastic Reed Sternberg cells of classical Hodgkin disease also express CD20 with a reported frequency ranging from less than $5 \%$ to more than $50 \%$ of tumors (4). Onconging clinical trials report encouraging results with the use of CD20 antibody (rituximab) particularly in lymphocyte predominant Hodgkin lymphoma $(1,5)$ where trials in relapsed disease have shown an overall response rate of $94 \%$ (1). Other trials, was rituximab as a single agent in refractory or recurrent $\mathrm{cHL}$, rituximab plus gemcitabine in refractory or recurrent $\mathrm{cHL}$, and rituximab plus $A B V D$ in newly diagnosed $\mathrm{CHL}{ }^{(6)}$. CD20 is involved in the regulation of human B-cell growth and differentiation (6). Rituximab targets the surface proteins of malignant Hodgkin cells and Reed Sternberg cells and eliminates the $C D 20$ reactive $B$ lymphocytes which support the Hodgkin Reed Sternberg cells in whom CD20 is also positive thus depriving the malignant cells of survival and causing cell death ${ }^{(6)}$.

The objective of this study was to have an idea about the mode of presentation, histopathological subtypes, treatment applied and outcome in one center in our country.

\section{Methods}

A retrospective descriptive study was done where by twenty cases (17 cases with initial remission and response to treatment, 3 cases refractory to treatment, non with relapse) were collected from the Pediatric Oncology Clinic in Al-Imamein AL-Kadhimein Medical City over a period of ten years from the first of January 2007 - end of December 2016. Information was taken from the patient's record in the Pediatric Oncology Clinic including age at presentation, sex, physical finding, histopathological subtypes, staging, treatment applied and outcome. Work up done including history looking for B symptoms as fever, night sweats and weight loss, investigations recorded including complete blood picture, liver function test, renal function test, chest X-ray, ultrasound and bone marrow examination; the diagnosis was established by lymph node excisional biopsy or fine needle aspirate, staging was done according to the Ann Arbor staging system (7). Chemotherapy was the mainstay of treatment; favorable response is considered when there is $(50 \%)$ or greater reduction in a measurable lymph node (8). Numerical data and percentage were estimated and tabulation were done using Microsoft Excel program.

\section{Results}

Among the studied group 14 cases (70\%) were males and 6 cases (30\%) were females, male: female ratio equal to $2.3: 1$, age range was between $5-12$ years with 12 cases (60\%) between 5-7 years as it is shown in table (1).

The initial presentation was an enlarged cervical lymph node in 19 cases (95\%) as it is shown in table (2).

Histopathological findings are shown in table (3), which showed that most of the patients had mixed cellularity subtype; 9 cases (45\%).

Staging is shown in table (4), stage II and stage III comprise the majority of cases, 9 cases (45\%) and 6 cases (30\%) respectively. B symptoms were reported in 7 cases (35\%). Chemotherapy was the mainstay of treatment even in stage I as these patients had the mixed cellularity 
subtype, as per the Hodgkin's disease UKCCSG protocol and the parents refused radiotherapy, ABVD (Adriamycin, Bleomycin, Vinblastine,
Dacarbazine) was used in 18 cases (90\%) with ABVP protocol (Adriamycin, Bleomycin, Vinblastine, Predinsolone) in 2 cases (10\%).

Table 1. Age at presentation and sex distribution

\begin{tabular}{ccccc}
\hline Age at presentation / years & No. & Male & No. & $\%$ \\
\hline$<5$ & $/$ & $/$ & $/$ & $/$ \\
$5-7$ & 9 & 45 & 3 & 15 \\
$8-10$ & 4 & 20 & 2 & 10 \\
$>10$ & 1 & 5 & 1 & 5 \\
\hline Total & 14 & 70 & 6 & 30 \\
\hline
\end{tabular}

Table 2. The initial presentation of patients

\begin{tabular}{ccc}
\hline Initial presentation & No. & \% \\
\hline Cervical lymph node enlargement & 19 & 95 \\
Axillary lymph node enlargement & 0 & 0 \\
Inguinal lymph node enlargement & 0 & 0 \\
Parotid mass & 1 & 5 \\
Pallor & 3 & 15 \\
Hepatomegaly & 3 & 15 \\
Splenomegaly & 3 & 15 \\
Mediastinal mass & 1 & 5 \\
Para aortic lymph nodes & 3 & 15 \\
Bone marrow involvement & 0 & 0 \\
\hline Total & 20 & 100 \\
\hline
\end{tabular}

Note: Some patients had more than one physical finding as initial presentation

Table 3. Histopathological sub types

\begin{tabular}{ccc}
\hline Histopathological sub types & No. & \% \\
\hline Mixed cellularity & 9 & 45 \\
Lymphocyte predominant & 7 & 35 \\
Nodular sclerosis & 4 & 20 \\
Lymphocyte depletion & $/$ & $/$ \\
\hline Total & 20 & 100 \\
\hline
\end{tabular}


Table 4. Staging of the disease at diagnosis

\begin{tabular}{cccc}
\hline Stage & No. & \% \\
\hline I & 5 & 25 \\
II & 9 & 45 \\
III & 6 & 30 \\
IV & 0 & 0 \\
\hline Total & 20 & 100 \\
\hline
\end{tabular}

No patient received radiotherapy as it is shown in table (5), 17 cases (85\%) showed good response with complete remission and cure, three cases $(15 \%)$ were refractory to the initial treatment with no response as shown in table (6). Refractory cases received alternate ABVD and ChIVPP (Chlorambucil, Vinblastine, Procarbazin, prednisolone) but they were resistant to treatment, review of the histological subtype revealed lymphocyte predominant subtype and positive CD20, so rituximab was added, the response to rituximab was good with remission and cure noticed as it is shown in table (5).

The outcome of the treatment is shown in table (6), 17 cases (85\%) showed complete remission with good response to treatment and were cured, 3 cases (15\%) were refractory to treatment, they responded well after rituximab was added, underwent complete remission and cured, no one relapsed and no death reported.

Table 5. Treatment applied for the patients with Hodgkin disease

\begin{tabular}{cccc}
\hline & Protocol applied & No. & $\%$ \\
\hline \multirow{3}{*}{ Newly diagnosed } & ABVD & 18 & 90 \\
& ABVP & 2 & 10 \\
Refractory to initial & Radiotherapy & 0 & 0 \\
treatment & Alternate ABVD and ChVIPP + & 3 & 15 \\
\hline Total & Rituximab* & 20 & 100 \\
\hline
\end{tabular}

*Rituximab added to refractory cases with positive CD20

Note: Total patients were 20, 3 of them were refractory and received new protocol of chemotherapy plus rituximab

\section{Discussion}

In this study, the age of the patients ranges between (5-12) years with a peak age at presentation of (5-7) years, which is nearly equal to a study done in Iran, 2002 (5-9 year) (9) but younger than the French study (4-16 year), $2003^{(10)}$ as well as a study done in Korea, 2012 (more than 16 years) ${ }^{(11)}$.
Males were affected more than females, which goes with that reported by studies done in USA, Iran, France $(1,9,10)$ and that reported by the National Cancer Institute (12).

Cervical lymph node involvement is reported in (95\%) of cases, which goes with studies done in USA and Bulgaria respectively ${ }^{(1,13)}$. 
Table 6. Outcome of the disease according to the stage of the disease

\begin{tabular}{ccccccc}
\hline Stage & $\begin{array}{c}\text { No. of patients with } \\
\text { favorable response } \\
\text { and complete } \\
\text { remission }\end{array}$ & $\begin{array}{c}\text { No. of } \\
\text { patients } \\
\text { who } \\
\text { refuse } \\
\text { treatment }\end{array}$ & $\begin{array}{c}\text { No. of } \\
\text { refractory } \\
\text { cases } \\
\text { (received } \\
\text { rituximab) }\end{array}$ & $\begin{array}{c}\text { No. of } \\
\text { relapsed } \\
\text { cases }\end{array}$ & $\begin{array}{c}\text { No. of } \\
\text { patient } \\
\text { lost to } \\
\text { follow up }\end{array}$ & $\begin{array}{c}\text { No. of } \\
\text { death }\end{array}$ \\
\hline I & 5 & 0 & 0 & 0 & 0 & 0 \\
II & 8 & 0 & 1 & 0 & 0 & 0 \\
III & 4 & 0 & 2 & 0 & 0 & 0 \\
IV & 0 & 0 & 0 & 0 & 0 & 0 \\
\hline Total & 17 & 0 & 3 & 0 & 0 & 0 \\
$\%$ & 85 & 0 & 15 & 0 & 0 & 0 \\
\hline
\end{tabular}

The most common histopathological subtype was mixed cellularity (45\%) indicating more severe and more aggressive disease, this pattern is similar to that reported in other countries. It was (66.7\%) in South Iran ${ }^{(9)},(50 \%)$ in South Taiwan ${ }^{(14)}$, (28\%) in Jordan ${ }^{(15)},(25 \%)$ in the United Kingdom ${ }^{(16)}$. Where in Jordan and United Kingdome the most common histopathological subtype was nodular sclerosis, $(49 \%, 66 \%)$ respectively ${ }^{(15,16)}$.

Most of the patients were stage II and III (75\%) compared with other studies stage II and III were $(65.8 \%)$ in Iran ${ }^{(9)}$ while in the French study the majority (89\%) were stage I and II (10) and in the Istanbul study (54\%) were stage I-II and (46\%) were stage III-IV (17). This may be explained by the parents' awareness when noticing abnormal and unusual lymph node enlargement and early referral by doctors to the oncology centers. Thirty-five percent had B symptoms, which is less than studies done in Iran (57\%) ${ }^{(9)}$ and Istanbul (46\%) ${ }^{(17)}$. This may be explained by the younger age group of our patients as older patients are more likely to have $B$ symptoms at presentation ${ }^{(9)}$.

Radiation therapy was not used as parents refused in some cases, or the early appointments were not available of note, current children oncology group trials investigated whether radiation therapy can be eliminated altogether in patients who have good rapid and early response to pre-radiation induction chemotherapy ${ }^{(1)}$.
Chemotherapy was not regularly available; the parents need to buy some of them from private pharmacies.

Chemotherapy was the mainstay of treatment with complete remission and response reported in (85\%) of cases. This can be explained by the use of $A B V D$ and $A B V P$ protocols both of which were found to be very effective chemotherapy for the treatment of Hodgkin lymphoma (1,7). Alternate ABVD, ChIVPP are good combination for refractory cases ${ }^{(7)}$ but because of resistance to treatment Rituximab was added, particularly after the cases were found to be of lymphocyte predominant subtype with positive CD20 (1). In this study the response to treatment after adding rituximab in refractory cases was good in term of remission and disappearance of the mass in the three refractory cases (15\%). In comparison with studies done elsewhere, Oki showed promising early results with rituximab. (6) while King et al showed that in patients with advanced-stage (III-IV) disease, there was no significant difference between rituximab and non-rituximab therapies ${ }^{(18)}$.

This study concluded that male predominance was noticed with younger age group at presentation. The majority presented with enlarged cervical lymph node. Although mixed cellularity was encountered in most of the patients, the response to chemotherapy was good. Rituximab can be used along with 
chemotherapy for refractory cases and for lymphocyte predominant Hodgkin lymphoma.

\section{Acknowledgments}

To all children with malignancy who fight for their survival.

\section{Author Contribution}

Both authors contributed to this manuscript. They coordinated study recruitment, implementation and progress of this study and helped with data interpretation and manuscript organization and editing.

\section{Conflict of interest}

The authors have no conflict of interest.

\section{Funding}

Self-funding.

\section{References}

1. Hochberg J, Giulino-Roth L, Cairo MS. Hodgkin lymphoma. In: Kleigman RM, Stanton BF, Schor NF (eds). Nelson Textbook of Pediatrics. 20 ${ }^{\text {th }}$ ed. Philadelphia: Elsevier, WB Saunders company; 2016. p. 2445-7.

2. Percy $C L$, Smith $M A$, Linet $M$, et al. Lymphomas and reticuloendothelial neoplasms. In: Ries LA, Smith MA, Gurney JG, et al. (eds). Cancer incidence and survival among children and adolescents: United States SEER Program 1975-1995. Bethesda, Md: National Cancer Institute, SEER Program, 1999. p. 35-50.

3. Piccaluga PP, Agostinelli C, Gazzola A, et al. Pathobiology of Hodgkin lymphoma. Adv Hematol. 2011; 2011: 920898. doi: 10.1155/2011/920898.

4. Raj JA, Bhuvaneshwari. Diagnosis of Hodgkin disease. Int J Sci Res. 2017; 6(6): 1895-7.

5. Shanker AG, Kirkwood AA, Hall GW, et al. Childhood and adolescent lymphocyte predominant Hodgkin lymphoma: A review of clinical outcome based on histopathological variant. $\mathrm{Br} J$ Haematol. 2015; 171(2): 254-262. doi: 10.1111/bjh.13540.

6. Oki $Y$, Younes $A$. Does rituximab have a place in treating classic Hodgkin lymphoma? Curr Hematol Malig Rep. 2010; 5(3): 135-9. doi: 10.1007/s11899010-0052-z.

7. United Kingdom Children's Cancer Study Group, Hodgkin disease protocol. 1999. p. 1-18.

8. Moghbel MC, Kostakoglu L, Zukotynski K, et al. Response assessment criteria and their applications in lymphoma: Part 1. J Nucl Med. 2016; 57(6): 92835. doi: 10.2967/jnumed.115.166280.
9. Karimi M, Yarmohammadi $H$, Ghavanini $A A$, et al. Epidemiological surveillance of pediatric Hodgkin disease in South Iran. Med Sci Monit. 2002; 8(8): CR572-5.

10. Pellegrino B, Terrier Lancomb MJ, Obelin O, et al. Lymphocyte predominant Hodgkin lymphoma in children, therapeutic abstention after initial lymph node resection, A study of French Society of Pediatric Oncology. J Clin Oncol. 2003; 21(15), 2948-52. doi: 10.1200/JCO.2003.01.079.

11. Won YW, Kwon JH, Lee SI, et al. Clinical features and outcomes of Hodgkin lymphoma in Korea: Consortium for Improving Survival of Lymphoma (CISL). Ann Hematol. 2012; 91(2): 223-33. doi: 10.1007/s00277-011-1297-x.

12. Ries LA, Kosary CL, Hankey BF, et al. SEER Cancer Statistics Review 1973-1995. Bethesda, Md: National Cancer Institute, 1998. Last accessed August 30, 2017.

13. Petkova $M$, Stanimirov $P$, Videnova L. Hodgkin disease in children - a clinical case. Int J Sci Res. 2017; 6(11): 810-813.

14. Chuang SS, Lin CN, Li CY. Malignant lymphoma in South Taiwan according to Revised European American classification of lymphoid neoplasm. J. Cancer. 2000: 89(7): 1586-92. doi: https://doi.org/10.1002/1097-

0142(20001001)89:7<1586::AID-CNCR24>3.0.CO;2-1.

15. Sughayer MA, Haddad HA, Al-Yousef RA, et al. Epstein-Barr virus and Hodgkin lymphoma in Jordan, Hematol Oncol Stem Cell Ther. 2014; 7(2): 85-9. doi: 10.1016/j.hemonc.2013.

16. Nachman GB, Spoto R, Herzog $P$, et al. Randomized comparison of low dose involved field radiotherapy and no radiotherapy in children with Hodgkin disease who achieve a complete response to chemotherapy. J Clin Oncol. 2002; 20(18): 3765-71. doi: 10.1200/JCO.2002.12.007.

17. Kebudi R, Buyukkapu SB, Gorgun O, et al. Risk adapted treatment in childhood Hodgkin lymphoma: outcome and changing epidemiologic features in 25 years. Blood. 2016; 128: 4158.

18. King MT, Donaldson SS, link MP, et al. Management of lymphocyte predominant Hodgkin lymphoma in modern era. Int J Radiat Oncol Biol Phys. 2015; 92(1): 67-75. doi: 10.1016/j.ijrobp.2015.02.001.

\section{Correspondence to Dr. Sawsan S. Abbas E-mail: sawsansati@yahoo.com saw-195@colmed-alnahrain.edu.iq Received May $15^{\text {th }} 2018$ Accepted Sep. $27^{\text {th }} 2018$}

